\title{
Recent insights into the origins of adrenal and sex steroid receptors
}

\author{
M E Baker \\ Department of Medicine, 0823, University of California, San Diego, 9500 Gilman Drive, La Jolla, CA 92093-0823, USA \\ (Requests for offprints should be addressed to M E Baker; Email: mbaker@ucsd.edu)
}

\begin{abstract}
The recent cloning by Thornton (2001) of estrogen, progesterone and corticoid receptors from lamprey provides important insights into the early evolution of adrenal and sex steroid receptors and an opportunity to elucidate the ancient steroids that regulated gene transcription. Inclusion of lamprey sequences in a steroid receptor phylogeny indicates that the estrogen receptor is the most ancient of these receptors, followed by the progesterone receptor and the corticoid receptor. Thornton proposed that estradiol was the earliest of the steroids to activate a steroid receptor. An alternative hypothesis is that a steroid in the $\Delta^{5}$ pathway activated the ancestral estrogen receptor.
\end{abstract}

Journal of Molecular Endocrinology (2002) 28, 149-152

\section{Introduction}

In the last few years, the origins of adrenal and sex steroid signaling have emerged as the sequences for the genes of androgen, estrogen, glucocorticoid, mineralocorticoid and progesterone receptors (AR, ER, GR, MR and PR, respectively) from mammals, amphibia and fish have been determined. Sequence analyses show that steroid receptors belong to the nuclear receptor family, a large diverse family of transcription factors (Laudet 1997, Owen \& Zelent 2000). The nuclear receptor superfamily also contains receptors for thyroid hormone, prostaglandins, 1,25-dihydroxy-vitamin D3 and xenobiotics, as well as receptors with no known ligand, which are called orphan receptors (Enmark \& Gustafsson 1996).

The importance of steroid receptors and other nuclear receptors in reproduction, differentiation, development and homeostasis in vertebrates provided an early stimulus for cloning and sequencing these proteins from a variety of multicellular animals. Thus, even 10 years ago, there was a sufficient number of diverse nuclear receptor sequences to allow a comprehensive phylogenetic analysis (Laudet et al. 1992), which showed that the adrenal and sex steroid receptors form a separate clade, distinct from other nuclear receptors. The $\mathrm{AR}, \mathrm{PR}, \mathrm{GR}$ and MR are in one subgroup and the $\mathrm{ER}$ is in a separate subgroup. In the following years, sequences from amphibia and teleosts (jawed fish) became available, which further clarified early events in steroid receptor evolution. These analyses showed that the AR and PR cluster were in one subgroup, and the MR and GR cluster in another subgroup (Baker 1997, Laudet 1997, Escriva et al. 1997). The phylogenetic tree indicated that an ancestral steroid receptor arose in a protochordate, such as a cephalochordate (e.g. amphioxus) or a urochordate (e.g. tunicate). If steroid receptors arose after the separation of deuterostomes and protostomes, then invertebrates such as Caenorhabditus elegans and Drosophila, which have nuclear receptors, would not have adrenal and sex steroid receptors (Baker 1997). Analysis of the genomes of C. elegans (Sluder \& Maina 2001) and Drosophila supports this prediction (Robinson-Rechavi et al. 2001). 
The patterns of the phylogenetic tree for steroid receptors indicate that there were two waves of gene duplications in the early evolution of steroid receptors (Baker 1997, Laudet 1997, Escriva et al. 1997, 2000). These duplications are proposed to be associated with genome size duplications that occurred early in the evolution of vertebrates (Holland 1999, Shimeld \& Holland 2000).

The availability of a variety of nuclear receptor sequences was exploited by Escriva et al. (1997) to investigate when steroid receptors and other ligandbinding nuclear receptors arose. Escriva et al. (1997) constructed PCR primers to the highly conserved DNA binding domain on a variety of nuclear receptors, which were used to probe for their presence in deuterostomes and protostomes, including diploblasts, such as jelly fish. Escriva et al. (1997) found AR, ER, GR, and PR ancestors in teleosts and sharks. They found a PR ancestor in hagfish, a jawless fish. No adrenal and sex steroid receptors were found in invertebrates. Interestingly, the estrogen-related receptor (ERR), a sister group of the ER for which a ligand has not been identified, was found in a cephalochordate and in a urochordate. Escriva et al. (1997) gave strong experimental support for the hypothesis that steroid receptors are a 'recent' evolutionary innovation, arising in a deuterostome prior to or at the base of the Cambrian explosion about 540 million years ago.

However, further analysis of steroid receptor sequences from organisms that are deeper in the metazoan phylogeny is needed to clarify the origins of adrenal and sex steroid receptors. Thus, the recent report by Thornton (2001) of the cloning of estrogen, corticoid (CR), and progesterone receptors from lamprey, a jawless fish, is an important advance in understanding the origins of adrenal and sex steroid hormone signaling. The lamprey steroid receptor sequences were used by Thornton to construct a comprehensive phylogenetic tree of vertebrate steroid receptors. The branch lengths clearly show that the ER is the ancestral receptor of the adrenal and sex steroid receptor clade of the nuclear receptor family. While ERR was not shown in the phylogeny, Thornton's analysis implies that ERR also is close to the ancestral steroid receptor. Duplication of this ancestral ER and divergence of the redundant gene led to a 3-ketosteroid receptor that most resembles the PR. Duplication of the ancestral 3-ketosteroid receptor and divergence led to the GR, which most resembles the GR.
An intriguing proposal by Thornton (2001) is that estradiol is the ancestral ligand of the ER. As Thornton notes, estradiol is the last steroid in the pathway for synthesis of steroid hormones (Fig. 1). Selection for estradiol also selects for the intermediates, such as progesterone and testosterone despite the absence of their receptors. These upstream steroids began to regulate transcription after duplication and divergence of the ancestral ER to form the PR and the subsequent descent of the AR from a duplicated PR. Thornton calls this process ligand exploitation, in which the ligand is a driving force in the functional evolution of its receptor.

Also consistent with ligand exploitation, but simpler from the viewpoint of steroid synthesis, is the hypothesis that the ancestral ER was activated by a $\Delta^{5}$-steroid that is upstream of estradiol (Fig. 1) (Baker 2001a). For example, $\Delta^{5}$-androstenediol has long been known to have estrogenic activity (Huggins et al. 1954) and to bind to the ER (Garcia \& Rochefort 1979). Kuiper et al. (1997) showed that $\Delta^{5}$-androstenediol and $3 \beta$-androstanediol bind to recombinant rat $\operatorname{ER} \alpha$ and $\operatorname{ER} \beta$ with nanomolar affinity. They also found that androgens with $3 \alpha$-alcohols have substantially lower affinity for the ER. Moreover, Miyamato et al. (1998) showed that $\Delta^{5}$-androstenediol can regulate estrogen-responsive genes by binding to the ER. This may be 'fossil' evidence for one or more ancestral steroids with a saturated A-ring containing a $3 \beta$ alcohol that activated the ancestral ER. It is not unreasonable to suppose that the ER, as well as PR and CR, in lamprey and in primitive fish has different ligand binding specificity than their orthologs in mammals and other land vertebrates. Indeed, fish PR recognizes $17 \alpha-$ hydroxy-progestins (Todo et al. 2000), unlike the $\mathrm{PR}$ in mammals.

The above hypothesis does not require that the ER-containing organism express a $3 \beta / \Delta^{5-4}$ hydroxysteroid dehydrogenase $\left(3 \beta / \Delta^{5-4}-\mathrm{HSD}\right)$ that catalyzes the formation of $\Delta 4$ steroids (Simard et al. 1996), which are precursors of estradiol (Fig. 1). Our recent BLAST database search (Altshul et al. 1997) did not find any proteins with at least 35\% sequence identity to $3 \beta / \Delta^{5-4}$-HSD in $D$. melanogaster, $C$. elegans or any other invertebrate (not shown). $3 \beta / \Delta^{5-4}$-HSD is found in mammals and trout (Sakai et al. 1994). Sequences with over $40 \%$ identity to a known $3 \beta / \Delta^{5-4}$-HSD are found in 


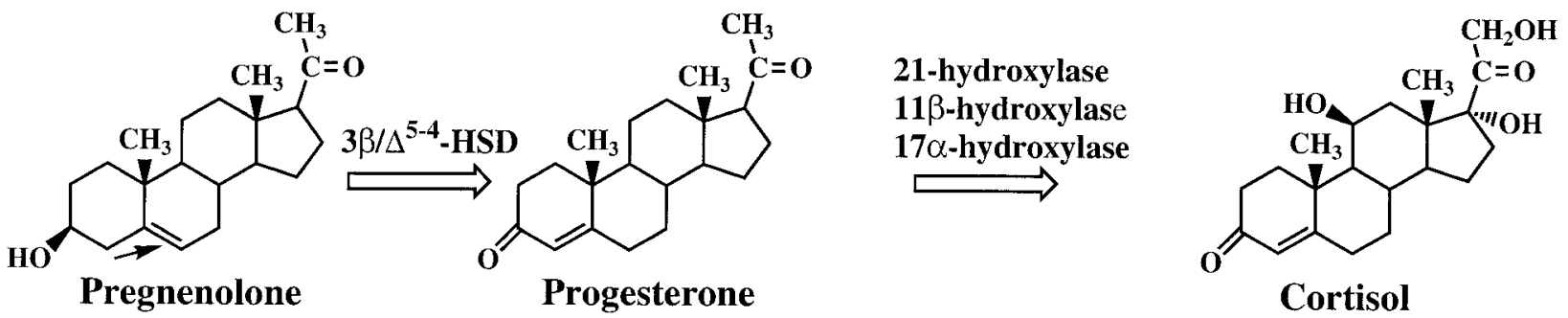

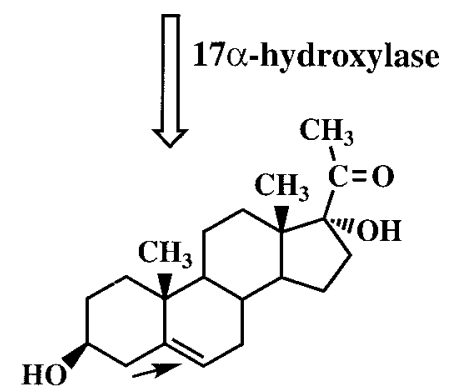

17 $\alpha$-hydroxypregnenolone

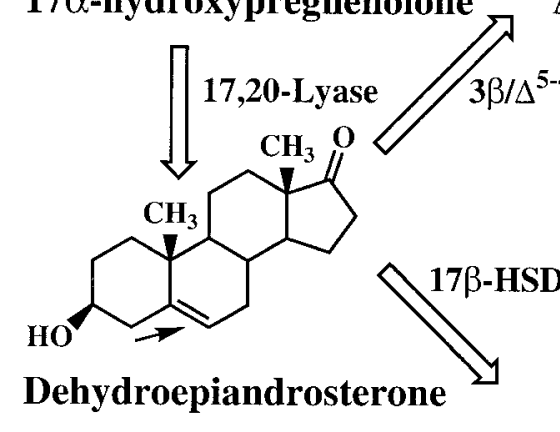

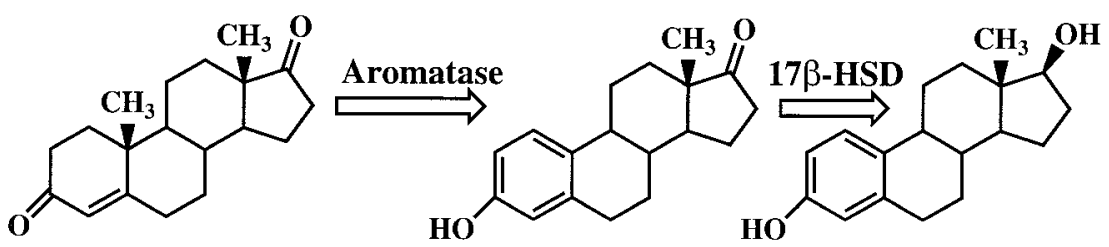

Androstenedione

Estrone

$17 \beta$-Estradiol

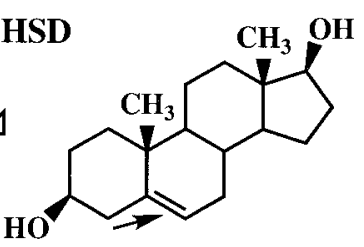

Androstenediol

Figure 1 Pathway for the synthesis of adrenal and sex steroids. Steroids in the $\Delta^{5}$ pathway are formed from pregnenolone by enzymes that are also found in the $\Delta^{4}$ pathway. An arrow denotes the $\Delta^{5}$ position. $3 \beta / \Delta^{5-4}$ hydroxysteroid dehydrogenase is the enzyme that converts $\Delta^{5}$ steroids to $\Delta^{4}$ steroids.

cartilaginous fish. These data are consistent with the ancestral ER arising prior to the evolution of $3 \beta / \Delta^{5-4}$-HSD that converted $\Delta^{5}$ steroids to $\Delta^{4}$ steroids in the pathway for estradiol synthesis. Diversification of steroid receptors would occur with the evolution of a $3 \beta / \Delta^{5-4}$-HSD that catalyzed the conversion of pregnenolone to progesterone, providing ligands that would regulate transcriptional activity of the ancestral PR and its descendents, the GR and AR. Indeed, the early evolution of steroid hormone action depended on $3 \beta / \Delta^{5-4}$-HSD and other hydroxysteroid dehydrogenases (Baker 2001b), as well as duplications of ancestral steroid receptors.

\section{What next?}

Investigation of the binding of various $\Delta^{4}$ and $\Delta^{5}$ steroids to lamprey ER, PR and CR will elucidate how these receptors compare with their orthologs in mammals and other land vertebrates, providing clues to the ancient ligands that regulated steroid hormone responses. In particular, analysis of the binding of estradiol and of $\Delta^{5}$ steroids with $3 \alpha$ and $3 \beta$-alcohols to lamprey ER and the activity of these steroids in assays with lamprey ER and a reporter gene will clarify the nature of the ligand(s) that bound to the ancestral steroid receptor. Further information about the earliest steroid 
receptors and the origins of $3 \beta / \Delta^{5-4}$-HSD will come from the sequencing of the genomes of amphioxus, hagfish and lamprey. It also will facilitate identifying the genes that were regulated by the ancestral steroid receptors. Of special interest are hox genes, which are regulated by estrogens and progestins in mammals and are critical for development and differentiation, including the brain of amphioxus (Manzanares et al. 2000). When did steroids begin to regulate expression of hox genes? By providing tools for answering this question, the identification of steroid receptors in lamprey is bringing us to the threshold of a deeper understanding of the origins of adrenal and sex steroid action.

\section{References}

Altshul SF, Madden TL, Schaffer AA, Zhang Z, Miller W \& Lipman DJ 1997 Gapped BLAST and PSI-BLAST: a new generation of database search programs. Nucleic Acids Research $\mathbf{2 5}$ 2167-2173.

Baker ME 1997 Steroid receptor phylogeny and vertebrate origins. Molecular and Cellular Endocrinology 135 101-107.

Baker ME 2001 a Adrenal and sex steroid receptor evolution: environmental implications. Fournal of Molecular Endocrinology 26 119-125.

Baker ME $2001 b$ Hydroxysteroid dehydrogenases: ancient and modern regulators of steroid hormone action. Molecular and Cellular Endocrinology 175 1-4.

Enmark E \& Gustafsson JA 1996 Orphan nuclear receptors - the first eight years. Molecular Endocrinology 10 1293-1307.

Escriva H, Safi R, Hanni C, Langlois M-C, Saumitou-Laprade P, Stehelin D, Capron A, Pierce R \& Laudet V 1997 Ligand binding was acquired during evolution of nuclear receptors. PNAS $\mathbf{9 4}$ 6803-6808.

Escriva H, Delaunay F \& Laudet V 2000 Ligand binding and nuclear receptor evolution. BioEssays 22 717-727.

Garcia M \& Rochefort H 1979 Evidence and characterization of the binding of two $3 \mathrm{H}$-labeled androgens to the estrogen receptor. Endocrinology 104 1797-1804.

Holland PW 1999 Gene duplication: past, present and future. Seminars in Cell and Developmental Biology 10 541-547.

Huggins C, Jensen EV \& Cleveland AS 1954 Chemical structure of steroids in relation to promotion of growth of the vagina and uterus of the hypophysectomized rat. Fournal of Experimental Medicine 100 225-240.

Kuiper GG, Carlsson B, Grandien K, Enmark E, Häggblad J, Nilsson S \& Gustafsson JA 1997 Comparison of the ligand binding specificity and transcript tissue distribution of estrogen receptors alpha and beta. Endocrinology 138 863-870.

Laudet V 1997 Evolution of the nuclear receptor superfamily: early diversification from an ancestral orphan receptor. Fournal of Molecular Endocrinology 19 207-226.

Laudet V, Hänni C, Coll J, Catzeflis F \& Stéhelin D 1992 Evolution of the nuclear receptor gene superfamily. EMBO fournal $\mathbf{1 1}$ $1003-1013$

Manzanares M, Wada H, Itasaki N, Trainor PA, Krumlauf R \& Holland PW 2000 Conservation and elaboration of Hox gene regulation during evolution of the vertebrate head. Nature $\mathbf{4 0 8}$ $854-857$.

Miyamoto H, Yeh, S, Lardy H, Messing E \& Chang C 1998 $\Delta 5$-Androstenediol is a natural hormone with androgenic activity in human prostate cancer cells. PNAS 95 11083-11088.

Owen GI \& Zelent A 2000 Origins and evolutionary diversification of the nuclear receptor superfamily. Cellular and Molecular Life Sciences $\mathbf{5 7}$ 809-827.

Robinson-Rechavi M, Carpentier A-S, Duffraisse M \& Laudet V 2001 How many nuclear hormone receptors are there in the human genome? Trends in Genetics 17 554-556.

Sakai N, Tanaka M, Takahashi M, Fukada S, Mason JI \& Nagahama Y 1994 Ovarian 3ß-hydroxysteroid dehydrogenase/ $\Delta 5$-4-isomerase of rainbow trout. Its cDNA cloning and properties of the enzyme expressed in a mammalian cell. FEBS Letters 350 309-313.

Shimeld SM \& Holland PW 2000 Vertebrate innovations. PNAS 97 4449-4452.

Simard J, Durocher F, Mébarki F, Turgeon C, Sanchez R, Labrie Y, Couet J, Trudel C Rhéaume E, Morel Y, Luu-The V \& Labrie F 1996 Molecular biology and genetics of the $3 \beta$-hydroxysteroid dehydrogenase/ $\Delta 5-\Delta 4$ isomerase gene family. Fournal of Endocrinology 150 (Suppl) S189-S207.

Sluder AE \& Maina CV 2001 Nuclear receptors in nematodes: themes and variations. Trends in Genetics 17 206-213.

Thornton JW 2001 Evolution of vertebrate steroid receptors from an ancestral estrogen receptor by ligand exploitation and serial genome expansions. PNAS 98 5671-5676.

Todo T, Ikeuchi T, Kobayashi T, Kajiura-Kobayashi H, Suzuki K, Yoshikuni M, Yamauchi K \& Nagahama Y 2000 Characterization of a testicular 17 $\alpha, 20 \beta$-dihydroxy-4-pregnen3 -one (a spermiation-inducing steroid in fish) receptor from a teleost, Japanese eel (Anguilla japonica). FEBS Letters 465 12-17.

Received in final form 23 January 2002 Accepted 12 February 2002 